\title{
FACULTY \& STUDENT RETENTION: KEEPING OUR HBCU-UDC ALIVE DURING THE COVID-19 PANDEMIC
}

\author{
Arlene King-Berry, \& Carolene Eslyn Charles \\ Department Education, University of the District of Columbia (USA)
}

\begin{abstract}
There is a national crisis around recruiting and retaining students from HBCUs. The Journal of Blacks in Higher Education surveyed 64 of 100 HBCUs and found that only five of the schools surveyed graduated more than 50 percent of their students. The statistics are startling because HBCUs, some of which date to Reconstruction in the South after the Civil War (widely accepted as the period from 1865 to 1877), ostensibly was designed to improve an underserved community. Despite the large number of freshmen admitted each year to Historically Black Colleges and Universities (HBCU), a low number graduate (Tinto, 1993). It is, therefore, imperative that HBCUs implement strategies most likely to increase retention and persistence rates.

When it comes to taking a closer look at pedagogy and practice in teaching, the COVID-19 Pandemic has created innovative environments for faculty to assess the students. The new perspective has many faculties utilizing evidence-based practices regarding performance-based assessment and other innovative techniques to assess students learning. Online teaching \& learning and online assessment are likely to occupy a higher percentage of the future curriculum, which can be seen as a positive development for online learning.

A correlation assumed that university faculty satisfaction and fair promotion could have a positive effect on student retention and engagement with a comprehensive analysis of these studies. It is paramount to consider that not only was fundamental student engagement found of tremendous relevance, but the literature is evident that student engagement during the entire higher education experience also leads to higher student retention rates and increased institutional commitment (Burke, 2019).

This paper defines retention and persistence at HBCUs and presents the results of a systematic literature review that (a) identifies the challenges that impact student retention and persistence at HBCUs during the COVID-19 Pandemic and (b) delineates research-based practices/strategies recommended to address the academic, socio-emotional, and financial and health/wellness challenges of students attending HBCUs.
\end{abstract}

Keywords: Universal design, teaching strategies, HBCUs, retention, persistence COVID-19.

\section{Introduction}

Retention in higher education is typically defined as the continued enrollment of a student from the first year to the second year (Bean 1980, 1982; Cotton et al. 2017; Farrell 2009; Ishler and Upcraft 2005; Spady 1970; Tinto 1975, 1993). Persistence refers to the act of continuing towards an educational goal (e.g., earning a bachelor's degree). A study conducted by the National Clearinghouse Research center retention was defined as continued enrollment (or degree completion) within the same higher education institution in the fall semesters of a student's first and second year. Persistence, on the other hand, is continued enrollment (or degree completion) at any higher education institution - including one different from the institution of initial enrollment — in the fall semesters of a student's first and second year. (National Clearing House Research Center 2018).

The retention and persistence of minority students in HBCUs are especially critical given the historical context of HBCUs. HBCUs exist because of the United State's history of exclusion, segregation, and racism. With the end of slavery following the Civil War, African American citizens faced numerous challenges gaining access to higher education. Financial barriers and admissions policies made attendance at many colleges and universities nearly impossible for most African Americans. 
In general, the research presents a troubling picture of student persistence and retention. Fall 2017 entering college students aged 20 or younger had a persistence rate of 76.9 percent, down 2.1 percentage points from the Fall 2009 entering cohort. This group also showed the highest spread between persistence and retention rates, with about 15 percent, or one in seven students, enrolling in a different institution in their second fall term. Entering students 21 to 24 -years-old had a persistence rate of 57.6 percent. This data represents an increase of 3.5 percentage points over the Fall 2009 entering cohort. Students aged 25 or older at college entry had a persistence rate of 53.3 percent, a figure that has remained essentially flat across all cohort years shown here.

The outbreak of the COVID-19 virus forced a significant shift in university experiences for faculty and students that would have been unimaginable only months earlier. In March 2020, the Pandemic forced the closure of most U.S. university campuses, obliging millions of students to finish their semester via remote learning. The rapid pivot to remote learning required mastering new learning platforms and forms of communication. In addition, it required sudden and complete dependence on digital devices and steady internet connections. Although all students faced the challenges of adapting to novel conditions in the middle of a semester, not all students began that hasty transition on equal footing. (Katz, Jordan, \& Ognyanova, 2021). For example, students with disabilities were generally the last to gain access to eLearning platforms and forms of communication. Furthermore, the imposition of social distancing deepened the process of segregation and exclusion for individuals with disabilities and those from culturally and linguistically diverse groups.

\section{Design}

Criteria were developed to guide the final selection of articles. Following a review of six (6) textbooks, two were selected for inclusion in this review based on the following criteria: (a) the texts had recent publication dates (2018-2020); (b) they were among the most widely used in first-year experience courses and introductory special education courses, and (c) they provided up-to-date references and resources.

\section{Methodology}

Two questions were designed to gain a current perspective on the retention/persistence challenges of students attending HBCUs and the strategies for assisting them.

* Question 1: What challenges impact retention and persistence at HBCUs

* Question 2: What research-based practices/strategies reduce the impact of these challenges?

* Question 3: What teaching strategies will ameliorate the impact of COVID- on faculty and diverse learners?

With these research questions in mind, a systematic multi-step search for relevant literature was conducted. First, current textbooks used in the first-year experience and special education were reviewed to ascertain appropriate retention strategies. Second, a search for peer-reviewed journal articles was conducted on the ERIC system, using the keywords retention, retention strategies, COVID-19, first-year experience, HBCUs. Third, a Google Scholar search was conducted using the same keywords. These searches yielded critical information and numerous articles addressing the topics of concern. Anecdotal feedback regarding challenges and valuable strategies from the author's courses was also considered.

\section{Discussion}

\subsection{Challenges that impact student retention and persistence at HBCUs}

The review of selected literature revealed that myriad factors impact the retention and persistence of HBCU Students during the Pandemic. Academic, socio-emotional, and financial factors comprised three challenge categories most frequently cited as negatively impacting students' retention and persistence.

\section{1) Academic Challenges}

Research literature reviewed indicates that students from low socioeconomic backgrounds face several challenges to successful college/university matriculation. These challenges include low standardized test scores; inadequate study skills; and poor grades, unreliable internet, fluctuating governmental directives, unprepared faculty. Although all students faced the challenges of adapting to novel conditions in the middle of a semester, not all students began that hasty transition on equal footing. 
(Katz, Jordan, \& Ognyanova, 2021). Low-income students often come to college less academically prepared than their more advantaged peers, with troubling implications for racial achievement gaps.

As a result, universities wrestle with myriad problems in their attempts to manage the education of students with disabilities. They struggle to find creative ways and alternate solutions to providing needed services during the Pandemic while maintaining compliance with applicable laws and regulations (Kennedy, 2020). Teaching strategies and technology applications (Apps) congruent with the central principles of the Universal Design for Learning (UDL) educational framework have a vital role in addressing the educational needs of students and faculty during this difficult time. Thus, the purpose of the literature-based research described herein was to identify UDL-congruent teaching strategies and technology Apps that higher education personnel can utilize to deliver and support effective eLearning for students with various learning characteristics and challenges.

\section{2) Social-Emotional Challenges}

According to the literature reviewed, socio-emotional variables constituted a second major area of challenge for college students. Variables such as loneliness, stress, poor time management skills, problems at home, unsupportive social environment, substance abuse, negative encounters with the law, and other behavioral challenges were cited in relevant literature (Palmer, Davis, Hilton, 2009). Riddle (2017) maintained that time management, stress, and social problems were among the seven top challenges most first-year college students face.

\section{3) Financial Challenges}

Financial challenges play a significant role in the retention and persistence of college students, both directly and indirectly. For example, direct financial/economic challenges include a lack of monetary resources and regulations regarding students' eligibility to receive financial aid. However, financial concerns and obligations are often intimately linked to the college campus's lack of social and academic engagement (Richards \& Awokoya, 2012). Thus, by negatively impacting social and academic engagement, these challenges also indirectly impact student retention and persistence.

\subsection{Practices/strategies that address academic, socio-emotional, and financial challenges Academic Support Approaches, Practices, and Strategies}

This literature review yielded a wide variety of practices and strategies for addressing the academic, socio-emotional and financial challenges that impact student retention and persistence. Specifically, effectiveness data emerged regarding the following approaches, practices, and strategies.

Universal Design for Learning Principles (UDL). This inclusion principle provides a much-needed framework for meeting the needs of students regardless of cultural, linguistic, and ability diversity. UDL is a framework to improve and optimize teaching and learning for all people based on scientific insights into how humans learn. "Three essential elements of UDL are often considered when developing curriculum for learners with diverse abilities. These components are multiple means of representation, engagement, and expression." Gargiulo \& Bouck, (2020, p. 27).

Open Source Resources. This emerging technology is designed to promote proven pedagogical content using an open-source design wherein a university produces specific materials for students which they can access for free. Student performance and retention are enhanced by access to high-quality resources.

Learning Communities. Learning communities in the form of seminars, clusters of students taking two classes together, or professional studies groups are particularly successful for part-time students. Bombardieri (2018) credits three factors for the effectiveness of this approach with part-time students: (a) the relationships with other students that a learning community provides; (b) the community's connections to supportive resources such as mentoring and coaching; and (c) a more meaningful, satisfying academic experience than first-year students are likely to experience by taking only a couple classes at a time. 
Time Management Strategies. Time management - the way individuals manage the events in their life with regard to time - has been cited as one of the seven (7) top challenges first-year college students face (Riddle, 2017). King-Berry (2016) maintains that, much like money, time is both valuable and limited; it must be protected, used wisely, and budgeted. Based on her work with students attending an urban HBCU, King-Berry offers several strategies designed to start students on a productive time management journey: develop a Daily Log, establish priorities, ask for help, don't put off for tomorrow what one can do today, do not let external factors waste valuable time, regularly revisit priorities.

\section{$\underline{\text { Socio-Emotional Support Approaches, Practices, and Strategies }}$}

Welcoming Campus Climate. In order to improve retention, a welcoming campus climate for nontraditional students is imperative. Furthermore, HBCUs should ensure that many of the courses and programs geared toward nontraditional students are offered on their main campuses, rather than miles away in a branch location or a remote office (Palmer, 2009).

High-Quality Faculty. Gasman \& Arroyo (2019) suggest that faculty members may be "the most pivotal players for creating holistic institutional conditions that facilitate student success and student development," (p. 7). These authors maintain that students benefit greatly in their pursuit of higher education when an institution has a critical mass of faculty members who are exceptionally skilled in their content.

Mentoring. Student mentors can also contribute significantly to the success and well-being of new college enrollees. Often, peers are highly skilled at understanding students' unique challenges and can relate more closely than faculty and staff to these challenges, offering first-hand advice (Kahu, 2018).

Culturally Relevant Community-Based Curriculum. Culturally relevant pedagogy and instructional materials can play an essential role in HBCUs to systematically remove prejudices about race and class and honor students' diverse backgrounds. These curricula will serve as a source of pride and motivation for African American students, enhancing their educational experiences (Honoring Origins-Chiefs of Change, 2019).

\section{Economic/Financial Health and Wellness Approaches, Practices and Strategies}

Clear Health Care Options. As students grapple with the high cost of education, college/university students must determine whether a parent's insurance plan will adequately cover them. Myong (2019) has indicted four insurance options that college students have: (a) staying on their parents' plan, (b) choosing a student health plan, (c) choosing a marketplace plan, (d) qualifying for Medicaid. When students are admitted to a college or university, appropriate institutional personnel should discuss their insurance status with them and apprise them of their options.

Strategies for Sustaining Health and Wellness. It is incumbent on faculty advisors and health services personnel to ensure that incoming students are made aware of recommendations that can support the stamina, physical, mental and emotional well-being that will minimize health care costs and contribute to students' retention and persistence. Multiple sources, such as the National Society of High School Scholars, offer tips and recommendations for staying healthy in school.

\section{Conclusion}

Retention and persistence remain among the most significant challenges to the much-needed existence of HBCUs, especially during the COVID-19 Pandemic. To improve, HBCUs must respond aggressively and effectively to the academic, social-emotional, and financial challenges that negatively impact their students' ability to complete course requirements, receive passing grades, establish meaningful relations, and matriculate in accordance with their academic plan. Articles selected and presented in this literature review offered empirical strategies that can positively impact the retention and persistence of HBCU students regardless of their cultural, linguistic, or ability diversity if implemented. While much work remains to be done, hopefully, the information presented here will improve retention and persistent outcomes for HBCUs. 


\section{References}

Bombardieri, M. (2018.). A Promising Model to Boost Retention for Part-Time Students. Retrieved from: https://www.americanprogress.org/issues/educationpostsecondary/reports/2018/07/31/454239/promisingmodel-boost-retention-part-time-students

Gargiulo, R. M., \& Bouck, E. C. (2021). Special education in contemporary society: an introduction to exceptionality. Los Angeles: SAGE.

Gasman, M., Regla-Vargas, A., Sandoval, C., Samayoa, A. C., \& Nguyen, H. (2020), January 31). Contributions of Historically Black Colleges and Universities to the Production of Black Nurses. Retrieved from https:/www.healio.com/nursing/journals/jne/2020-2-59-2/\{5f097c28-ad33-4bfa9976-cc15dd4a7989\}/contributions-of-historically-black-colleges-and-universities-to-theproduction-of-black-nurses

Kahu, E., \& Lodge, J. (2018). Student Success. Retrieved from https://studentsuccessjournal.org/issue/view/69

Katz, V., Jordan, A., \& Ognyanova, K. (2021, February 02). Digital inequality, Faculty communication, and remote learning experiences during the Covid-19 pandemic: A survey of U.S. undergraduates. Retrieved February 12, 2021, from https://journals.plos.org/plosone/article?id=10.1371\%2Fjournal.pone.0246641

Kennedy, H. (2020, December 01). Special education in a pandemic: A legal and guideline summary for mediators and conflict resolution practitioners. Retrieved February 11, 2021, from https://www.mediate.com/articles/kennedy-spec-ed-pandemic.cfm

King-Berry, A. (2016). The Power of Time Management in Ensuring Success for Students from Traditionally Under-represented Groups in Higher Education. Process Education Conference Proceedings

Myong, E. (2019). Four ways for college students to manage their health-care costs. Retrieved from: https://www.cnbc.com/2019/09/03/four-ways-for-college-students-to-manage-their-health-carecosts.html

National Society of High School. (2018). 7 Tips for Staying Healthy in College. Retrieved from: https://www.nshss.org/blog/7-tips-for-staying-healthy-in-college/

NSC Research Center. (2019). Persistence \& Retention - 2017. Retrieved from: https://nscresearchcenter.org/snapshotreport28-first-year-persistence-and-retention/

Palmer, R. T., Davis, R. J., \& Hilton, A. A. (2009). Exploring Challenges That Threaten to Impede the Academic Success of Academically Underprepared Black Males at an HBCU. Journal of College Student Development, 50(4), 429-445. doi: 10.1353/csd.0.0078

Richards, D., Awokoya, J.T. (2012). Understanding HBCU Retention and Completion. Retrieved from: https://files.eric.ed.gov/fulltext/ED562057.pdf

Riddle, R. (2017, May 9). Top 7 Challenges Most College Freshmen Face. Retrieved from: https://www.youniversitytv.com/college-tips/top-7-challenges-college-freshmen-face/

Tinto, V. (2012). Completing College. Retrieved https://www.press.uchicago.edu/ucp/books/book/chicago/C/bo5514387.htm 